\title{
VIGENCIA DE LAS IDEAS DE JOSÉ CARLOS MARIÁTEGUI APUNTES PARA LA POLÉMICA
}

\author{
VALIDITY OF JOSÉ CARLOS MARIÁTEGUI'S IDEAS NOTES FOR CONTROVERSY
}

César Augusto Montes Aranda ${ }^{1}$

\begin{abstract}
RESUMEN
Este artículo trata de demostrar que las ideas fundamentales de José Carlos Mariátegui todavía siguen vigentes desde el punto de vista histórico. También se plantea la hipótesis de que el socialismo revolucionario y el marxismo dialéctico de José Carlos Mariátegui han sido traicionados por las diversas ideologías dogmáticas como el marxismo stalinista de Eudocio Ravines y Jorge del Prado, el marxismoleninismo-maoísmo, pensamiento Gonzalo del Partido Comunista de Sendero Luminoso y otras ideologías.
\end{abstract}

Palabras clave: Marxismo, marxismo dialéctico, marxismo-leninismo, marxismo stalinista, marxismo dogmático.

\section{ABSTRACT}

This research attempts to demonstrate that the fundamental ideas of José Carlos Mariátegui from the historical point of view still remain in force. The article also raises the hypothesis that revolutionary socialism and the dialectical Marxism of José Carlos Mariátegui have been betrayed by various dogmatic ideologies such as the Stalinist Marxism of Eudocio Ravines and Jorge del Prado, Marxism-Leninism-Maoism, Gonzalo Thought of the Communist Party of Shining Path and other ideologies.

Keywords: Marxism, dialectical marxism, marxism-leninism, stalinist marxism, dogmatic marxism.

\section{INTRODUCCIÓN}

La vigencia de Mariátegui no se encuentra en sus tesis históricas sobre la realidad peruana estudiadas fuera de su contexto histórico, ni en sus ideas políticas parafraseadas por los lectores sin pensamiento crítico, tampoco puede hallarse en sus párrafos epigramáticos citados textualmente como si fueran versículos de una Biblia que hay que aprender de memoria. Por el contrario, la actualidad del pensamiento de Mariátegui se encuentra en la manera de pensar el marxismo como un método dialéctico para analizar la realidad social, en el punto de vista del materialismo histórico como la interpretación económica de la historia, en la concepción del marxismo como una filosofía de la praxis cuyo objetivo fundamental es la transformación de la realidad, en el proyecto histórico en defensa del proletariado y en la propuesta del socialismo peruano no como calco ni copia sino como "creación beroica" y como alternativa frente al capitalismo salvaje.

\section{Primera tesis}

Los ideólogos del capitalismo se han equivocado de muerto

En 1960 Daniel Bell, un intelectual de la burguesía, publicó un libro emblemático titulado El fin de la ideología. Pero nosotros no creemos ese cuento.

Las ideologías que están en contra del socialismo nos quieren hacer creer que las ideas de Carlos Marx están en crisis. Pero como decía Galeano (1990) "se han equivocado de muerto.” Así, por ejemplo, los ideólogos del capitalismo siguen creyendo que están sepultando al socialismo, pero realmente ese difunto no es el nuestro porque no es el marxismo de Carlos Marx el que está en crisis si no el cadáver nauseabundo del stalinismo que se destruye en pedazos. Así también, tomando en cuenta esta idea planteamos que no es el marxismo dialéctico ni el socialismo como "creación heroica" de Mariátegui el que se encuentra en crisis sino el marxismo dogmático, petrificado y vulgar.

${ }^{1}$ Historiador e investigador independiente. Premio Nacional de Educación. E-mail: cesarmontes66@yahoo.com 


\section{Segunda tesis Influencias ideológicas en el pensamiento de José Carlos Mariátegui}

El marxismo de Mariátegui es una filosofía de la praxis que no contempla la realidad sino que tiene como objetivo la transformación de la sociedad. Sin embargo, existe un grupo de investigadores que tratan de domesticar el pensamiento revolucionario de Mariátegui.

No hay ninguna duda de que en el marxismo dialéctico de Mariátegui influenciaron varias ideas. Así, por ejemplo, el pensamiento revolucionario de Georges Sorel respecto a la importancia del mito político en la historia, la idea de la decadencia de la civilización capitalista de Oswald Spengler, la concepción de la historia de Benedetto Croce, las opiniones de Miguel de Unamuno sobre la agonía del cristianismo, y las frases lapidarias de Federico Nietzsche, influenciaron en el pensamiento del amauta; pero también no debemos olvidar que es imposible comprender la ideología de Mariátegui sin el método dialéctico y la concepción económica de la historia de Carlos Marx y sin la filosofía marxista y las tesis políticas de Lenin. En consecuencia, degeneran y traicionan las ideas de Mariátegui quienes pretenden dar mayor importancia al pensamiento de Sorel, Unamuno o Nietzsche, en contraposición a las ideas revolucionarias de Marx y Lenin.

\section{Tercera tesis}

Los 7 ensayos de interpretación de la realidad peruana

Antes de la publicación de los 7 ensayos de interpretación de la realidad peruana, se habían editado Pájinas libres de Manuel González Prada, El Perú contemporáneo de Francisco García Calderón y el libro Tempestad en los andes de Luis Valcárcel. La diferencia entre todos estos libros es que los 7 Ensayos era el único análisis marxista de la realidad peruana escrito por un intelectual socialista que tenía un proyecto revolucionario para transformar la sociedad peruana.

Los 7 Ensayos de Mariátegui sigue siendo un libro polémico. En cuanto al libro, existen dos tipos de lectores: los que creen que el libro de Mariátegui ya no tiene ningún valor, ninguna utilidad y los que afirman que, desde una perspectiva histórica, los 7 ensayos siguen teniendo vigencia porque los problemas planteados en el libro todavía no han sido solucionados y porque actualmente existen otros problemas como la pobreza, el desempleo, los salarios miserables y la injusta distribución de la riqueza en el Perú.

Los 7 ensayos de interpretación de la realidad peruana es el libro donde Maríategui aplica creativa- mente el método dialéctico y la concepción económica de la historia de Carlos Marx. Existen dos procedimientos para leer los 7 ensayos, el método dogmático y el método crítico. Quienes leen los escritos de Mariátegui como si fueran versículos de una Biblia que hay que aprender de memoria o quienes citan los textos del amauta como si fueran artículos de un código penal, se sumergen en el método dogmático. Por el contrario, leer críticamente a Mariátegui es concentrarse en cómo el amauta utilizó el método dialéctico marxista para analizar los problemas de la realidad peruana. Leer críticamente a Mariátegui no consiste en repetir sus tesis históricas y políticas al margen de su contexto histórico, tampoco significa leer la letra sino el espíritu de sus escritos revolucionarios.

\section{Cuarta tesis}

\section{Peruanicemos al Perú}

Desde septiembre de 1925 hasta mayo de 1929 Mariátegui escribió varios artículos en la sección "Peruanicemos al Perú" de la revista Mundial. Existen dos maneras para comprender esta interesante tesis histórica: la visión dogmática y el punto de vista dialéctico.

Peruanicemos al Perú no significa que hay que volver al pasado tradicional de los periodos románticos de nuestra historia. Tampoco quiere decir que el Perú se convierta en una isla apartada del escenario económico y social del mundo contemporáneo. Peruanicemos al Perú significa volver a nuestras raíces históricas, rescatar nuestros recursos naturales y distribuir la riqueza entre todos los peruanos, crear una democracia auténtica y no una democracia de caricatura, estar en contra de los que venden el Perú en pedazos. Pero también, peruanicemos al Perú significa fundar una nación donde no exista la explotación del hombre por el hombre.

\section{Quinta tesis}

El marxismo de Mariátegui es una filosofía de la praxis

En el libro Defensa del marxismo, José Carlos Mariátegui demostró que el marxismo no es una ideología dogmática y petrificada sino que es un método dialéctico y una concepción materialista de la historia. Pero también explicó que el marxismo es una filosofía de la praxis, es decir, una concepción de la filosofía que no contempla la realidad sino que une la teoría y la práctica con el objetivo de cambiar la sociedad.

Para Mariátegui el marxismo no es una filosofía de la historia pero sí es una interpretación económica de la historia y una filosofía de la praxis. Esta distinción indudable fue muy bien comprendida por el filósofo peruano 
Augusto Salazar Bondy en el capítulo "El pensamiento de Mariátegui y la filosofía marxista", texto contenido en el segundo tomo de su obra Historia de las ideas en el Perú contemporáneo.

En el artículo "Contribución a la crítica de la filosofía del derecho de Hegel", Carlos Marx escribió que "no podéis superar la filosofía sin realizarla." Pero también explicó que "la filosofía no puede llegar a realizarse sin la abolición del proletariado, y el proletariado no puede abolirse sin la realización de la filosofía” (1970, p.116). Desde nuestro punto de vista, Mariátegui también comenzó el camino revolucionario de la realización de la filosofía marxista en el Perú.

Pero, ¿qué es la filosofía de la praxis? La filosofía de la praxis es la posición partidaria en la lucha de clases, es la unión de la teoría y la práctica para el cambio social. Tiene una ideología: el marxismo y el leninismo. Un objetivo: la transformación de la sociedad capitalista y no la contemplación de la realidad. Una metodología: la lucha de clases, es decir, la realización de la filosofía como decía Carlos Marx.

La filosofía de la praxis de Mariátegui se encuentra en las conferencias que dictó en 1923 y 1924 en la Universidad Popular González Prada, conferencias que formaron la conciencia de clase en el proletariado peruano; en su trabajo apasionado como director de los periódicos La Razón y Labor y las revistas Claridad y Amauta, publicaciones revolucionarias que unieron al movimiento obrero y los intelectuales en la lucha contra la sociedad oligárquica; en la fundación del Partido Socialista Peruano, como el partido de la revolución socialista, en la organización de la Confederación General de Trabajadores del Perú y en las polémicas de Mariátegui con Víctor Raúl Haya de la Torre y con los dirigentes de la III Internacional Comunista.

\section{Sexta tesis \\ El Partido Socialista de Mariátegui}

El filósofo Jean Paul Sartre dijo una vez que "los partidos mueren cuando no siguen el curso de la historia" (Flores, 1983, p. 92). La frase es interesante; pero sería más adecuado decir que los partidos políticos mueren porque sólo siguen el rumbo de la historia cuando de lo que se trata es de cambiar el curso de la historia.

El Partido Socialista de Mariátegui tenía como fundamento la historia de la lucha de clases del movimiento obrero en el Perú y no fue creado para ser una organización exclusiva de un pequeño grupo de políticos profesionales, sino que fue fundado para convertirse en un partido de masas.

A diferencia de los partidos stalinistas de la III Inter- nacional Comunista, organizaciones políticas burocráticas, degeneradas y caducas y que, como la historia lo ha demostrado, traicionaron el marxismo dialéctico y la revolución socialista; el Partido Socialista de Mariátegui fue creado como vanguardia del movimiento obrero para realizar verdaderamente la revolución socialista en el Perú y no para traicionarla.

Por lo tanto, el Partido Socialista de Mariátegui era un proyecto político totalmente diferente de los partidos comunistas de Eudocio Ravines y Jorge del Prado, de los partidos de lo que fue Izquierda Unida en el Perú y también se diferencia radicalmente del Partido Comunista de Sendero Luminoso.

\section{Séptima tesis}

El socialismo revolucionario de Mariátegui

Así como en su libro La Alternativa, Rudolf Bahro afirmaba que "nuestro socialismo realmente existente es un orden fundamentalmente distinto al esbozado en la teoría socialista de Marx" (1980, p. 13). Así también, es necesario decir que el proyecto histórico del "socialismo indoamericano" de Mariátegui fue una alternativa política completamente diferente al socialismo stalinista de la III Internacional Comunista.

El "socialismo indoamericano" de Mariátegui es, una "peculiar articulación entre marxismo y nación" como dice Flores Galindo. Esto quiere decir que el socialismo del amauta es un proyecto histórico que tiene como fundamento la historia del Perú, la tradición cultural de las comunidades indígenas y la lucha de clases del movimiento obrero peruano.

Mariátegui planteó la tesis del "socialismo indoamericano" como una propuesta democrática para tratar de solucionar los problemas del Perú como nación. Y como todos sabemos, los problemas centrales de la sociedad peruana de la década de 1920 fueron los siguientes: la tara social del feudalismo y la servidumbre, el despotismo del estado oligárquico, la dominación de la burguesía imperialista, el problema de la tierra y la explotación indígena a través de las relaciones precapitalistas de producción como el yanaconaje y el enganche; la explotación del proletariado agrícola, minero y textil y finalmente una de las características centrales del Perú de la época de Mariátegui es que no sólo se caracterizó por la intensa lucha de clases en el campo entre la oligarquía terrateniente y los campesinos de la costa y, por otro lado, el dominio del gamonalismo sobre las comunidades campesinas de la sierra sino que no hay que olvidar "la guerra de razas" entre el campesino indio y el terrateniente blanco, problema social en la historia del Perú al que nosotros venimos 
calificando como la síntesis dialéctica entre la lucha de clases y los conflictos étnicos.

En cuanto a la palabra socialismo hay que tener en cuenta que Mariátegui utilizó este término para darle varios significados de acuerdo al objetivo concreto de su tema de investigación. Así, por ejemplo, para analizar su proyecto socialista empleó las siguientes frases: "socialismo marxista", "socialismo indoamericano", "socialismo peruano", "socialismo de las comunidades campesinas", "socialismo incaico" y "socialismo práctico.” Así también, para criticar al socialismo revisionista usó las siguientes denominaciones: "socialismo domesticado", "socialismo parlamentario", "socialismo humanitario" y "socialismo reformista."

En el libro Defensa del marxismo Mariátegui dijo que la "ética del socialismo se forma en la lucha de clases" (1994, t. I, p. 1305). Pero también escribió que el socialismo peruano no debe ser calco ni copia sino "creación heroica." Esto quiere decir que para el amauta el marxismo no es una teoría para la contemplación de los fenómenos sociales sino que es una "filosofía de la praxis" que sirve para la transformación de la realidad. En consecuencia, quienes piensan fundar un socialismo al margen de la lucha de clases que sigan construyendo castillos en el aire.

\section{Octava tesis}

\section{Augusto Salazar Bondy y el "marxismo abierto"} de Mariátegui

Augusto Salazar Bondy fue uno de los primeros filósofos peruanos que reconoció el carácter filosófico del marxismo de Mariátegui. En el capítulo "El pensamiento de Mariátegui y la filosofía marxista", texto contenido en el segundo tomo de su obra Historia de las ideas en el Perú contemporáneo, Salazar Bondy plantea la hipótesis de que el marxismo de Mariátegui fue un "marxismo abierto" en el sentido de que el amauta no solo fundamentaba sus ideas en el marxismo de Carlos Marx y Lenin sino que también aceptaba los aportes de otras ideologías como el pensamiento revolucionario de Georges Sorel y la filosofía de Henri Bergson.

Es indispensable indicar que a diferencia de David Sobrevilla que niega el método dialéctico marxista del amauta, la hipótesis sobre el "marxismo abierto" de Mariátegui no significa una ideología al margen de la filosofía marxista sino que es como dice Salazar Bondy "un pensamiento genuinamente dialéctico" (1972, p.58).

El filósofo Augusto Salazar Bondy publicó en el número 5 y 6 de la revista Textual, Lima, 1972, un interesante artículo titulado "Actualidad de Mariátegui."
El artículo es importante porque es uno de los más creativos replanteamientos de las ideas de Mariátegui sobre el problema educativo peruano. Pero también es uno de los ejemplos concretos de como una tesis del amauta puede servir de punto de partida para analizar y desarrollar un problema de investigación.

El propósito del mencionado artículo es tratar de demostrar que la idea central de Mariátegui, sobre el problema de la cultura y la educación en el Perú, todavía sigue vigente. Para lograr este objetivo Salazar Bondy analiza las opiniones educativas de Mariátegui sobre la educación peruana bajo el punto de vista de la teoría del subdesarrollo y de la interesante tesis de "la educación de la dominación".

Es necesario recordar que los argumentos críticos de Mariátegui en contra de las ideas de Alejandro Deústua y Manuel Vicente Villarán son elementales porque ayudaron a sintetizar su visión marxista sobre el problema de la educación en el Perú.

En la sociedad peruana en que vivió Mariátegui había tres concepciones sobre el problema de la educación en el Perú: En primer lugar, el análisis exclusivamente filosófico de Alejandro Deústua y que según el amauta representaba el "espíritu antidemocrático y antisocial" de "la vieja mentalidad aristocrática de la casta latifundista." (1952, p.160). En segundo lugar, la concepción liberal de la educación de Manuel Vicente Villarán y que según Mariátegui representaba el "programa del civilismo burgués." (1952, p.159). Y en tercer lugar tenemos la interpretación marxista del problema de la educación peruana representada por Mariátegui.

Según Salazar Bondy, "el aporte decisivo de Mariátegui es la necesidad de ver el conjunto del esfuerzo educativo y del quehacer cultural peruanos bajo la luz de la condición colonial de nuestro país; es decir, de las relaciones de dependencia que han sujetado al Perú desde la época de la conquista a un país dominador y que, en lo interno, han determinado relaciones de subordinación y de explotación que afectan a la gran mayoría de la población peruana e impiden la integración de la nación.” (1972, p. 19).

La explicación de Salazar Bondy es significativa porque para Mariátegui el problema educativo no está al margen de la realidad nacional y la traba social del colonialismo ideológico y económico de la sociedad peruana. En consecuencia, el problema de la educación en el Perú no es una cuestión filosófica, moral o estrictamente pedagógica sino que es un problema esencialmente económico y social.

En resumen, el análisis marxista de Mariátegui 
sigue vigente porque es una ilusión social tratar de solucionar el problema educativo en el Perú al margen de la injusticia social, del hambre de millones de peruanos, del desempleo de miles de ciudadanos, de los salarios miserables y de la explotación del trabajo de millones de peruanos.

\section{Novena tesis}

\section{Eudocio Ravines: un stalinista al revés}

La historia del Partido Comunista Peruano no solo se caracteriza por la traición del proyecto socialista en el Perú sino que también es la historia de la dogmatización y la falsificación de las ideas revolucionarias de Mariátegui.

La historia de las ideas stalinistas en el Perú comienza en 1930 cuando Eudocio Ravines fue nombrado Secretario General del Partido Comunista Peruano. La historia de Ravines es un caso interesante porque fue el político peruano mejor preparado en el periodo de la III Internacional Comunista que defendió el socialismo stalinista. Pero después se convierte en un "stalinista vuelto al revés" como escribió Isaac Deutscher en su libro Herejes y Renegados. Eudocio Ravines, el anticomunista peruano más implacable de la historia del Perú no solo renegó furiosamente contra el comunismo internacional sino que también se dedicó a erradicar el mariateguismo, traicionando el marxismo y el socialismo de Mariátegui.

Parece increíble la metamorfosis ideológica de Ravines. Para comprender este problema es necesario decir que hay dos Ravines. El Ravines antes de la muerte de Mariátegui y el Ravines después de la muerte del amauta. Desde que se conocieron, estos dos personajes históricos no solo fueron muy buenos amigos sino que además lucharon por el socialismo peruano; pero después Ravines traiciona a Mariátegui y se convierte en el primer sepulturero de las ideas revolucionarias de José Carlos Mariátegui.

Comprender la evolución ideológica de Eudocio Ravines es una cuestión difícil no solo por los problemas que uno encuentra al tratar de conseguir sus artículos sino porque además sus ideas van cambiando constantemente de acuerdo a las circunstancias históricas. Así por ejemplo, de 1927 hasta el año de 1929, Ravines colabora con la revista Amauta escribiendo cinco artículos sobre el imperialismo. Posteriormente a partir de 1930, es decir después de la muerte de Mariátegui, Ravines comienza la táctica de "clase contra clase”, aprobada en el VI Congreso de la Internacional Comunista celebrado el año de 1928. Al aplicar esta táctica stalinista en el Perú, Ravines une el Partido
Comunista Peruano al cordón umbilical de la III Internacional. Después, a partir de 1932, Ravines estuvo de acuerdo con la campaña política contra el "Mariateguismo." Luego en 1945 Ravines escribe un artículo muy importante titulado "El Mariateguismo", texto bellamente escrito donde defiende la ideología de Mariátegui. Pero doce años después, a fines de la década de 1950, en su revista Vanguardia, Ravines comienza a escribir la más implacable crítica que se haya planteado a las ideas de José Carlos Mariátegui.

En un artículo titulado "El marxismo, los siete Ensayos y Mariátegui”, Ravines dice que los 7 Ensayos de interpretación de la realidad peruana tiene "un mensaje que no solamente no es marxista, en absoluto, sino que es básica, rotundamente anti-marxista" (1957, p.6). Luego en el artículo titulado "La excomunión y la herejía de José Carlos Mariátegui”, el autor de La Gran Estafa afirma que "Mariátegui pues, en toda la integridad de su obra, no es, no se presenta, no parece, como un materialista marxista. Bien al contrario: es un idealista de tomo y lomo" (1958, p.7). Y después en el artículo titulado "Mariátegui no concibió la reforma agraria", escribe que "la interpretación de Mariátegui hiciera de la realidad peruana es deleznable ficticia y radicalmente falsa" (1958, p. 12). Así también, critica la tesis de Mariátegui de que la comunidad campesina es uno de los fundamentos del socialismo peruano. Al respecto Ravines puntualiza que "al exaltar beatamente la comunidad como solución o como vía de superación, Mariátegui hace sentimentalismo indigenista, lo que le conduce a la posición reaccionaria del que trabaja para hacer marchar hacia atrás el carro de la historia" (1958, p. 13). Estas son algunas de las tesis que demuestran como Ravines traiciona el pensamiento de Mariátegui.

Pero, ¿por qué Ravines traiciona a Mariátegui? ¿Por qué se convierte en un "stalinista al revés"?, es decir, en un anticomunista? La historia de los traidores del socialismo de Mariátegui comienza con Eudocio Ravines, el primer sepulturero de las ideas del amauta. Pero es necesario decir que Ravines no siempre fue un traidor sino que llegó a serlo porque fue traicionado por su propia ideología: el stalinismo.

Ravines fue un comunista combatiente que luchó por las ideas de Marx y Lenin. Siempre imaginó que en la Unión Soviética de la década de 1920 se estaba construyendo el socialismo; pero cuando visitó el país de la revolución rusa se dio cuenta de que el socialismo de Lenin estaba siendo derribado por Stalin.

El libro La gran estafa de Eudocio Ravines, es una obra fundamental en la historia de las ideas políticas en 
el Perú. En esta obra Ravines escribió que el partido comunista se ha transformado "en un parásito de la clase obrera" (1952, p.288). Así también, afirma que el comunismo se ha convertido en "una de las tiranías más sangrientas y voraces de la historia" (1952, p. 422). Y finalmente, después de su estadía en la Unión Soviética, en la década de 1920 y en los años de 1930 , Ravines llega a la conclusión de que el comunismo soviético es una maldita estafa social. Es por eso que escribe que "aquello no era el marxismo: era un prolongado y doloroso crimen, una monstruosa y grande mentira" (1952, p. 393). Fue precisamente en estas circunstancias históricas que Ravines se convierte en un anticomunista hasta los huesos. Pero el autor de $L a$ Gran Estafa no solo va a maldecir el comunismo internacional sino que en lugar de defender las ideas de José Carlos Mariátegui va a traicionarlo, iniciando la historia infame de los sepultureros del socialismo de Mariátegui.

\section{Décima tesis}

El Partido Comunista Peruano dirigido por Jorge del Prado y la interpretación stalinista del marxismo de Mariátegui

En la historia de las ideas políticas en el Perú no debemos olvidar los siguientes aspectos: En primer lugar, Mariátegui fundó en 1928 el Partido Socialista y no el Partido Comunista. En segundo lugar, tuvo serias discrepancias con la III Internacional Comunista. En tercer lugar, fue un marxista- leninista pero no stalinista. En cuarto lugar, el creador del socialismo peruano reconoció el talento político de Trotsky. Sin embargo, en sus libros Mariátegui y su obra y En los años cumbres de Mariátegui, Jorge del Prado, envuelto con su dogmatismo, trata de falsificar la realidad explicando que Mariátegui fundó el Partido Comunista, que no tuvo discrepancias con la III Internacional Comunista, que fue un "marxista-leninista-stalinista" y que condenó políticamente a Trotsky.

El marxismo de Mariátegui fue un marxismo dialéctico y creativo. Dialéctico en el sentido filosófico y también como doctrina contraria al dogmatismo que petrifica las ideas. Los 7 ensayos de interpretación de la realidad peruana, las revistas Amauta y Claridad, los periódicos La Razón y Labor y los centenares de artículos que escribió, demuestran el marxismo creativo y revolucionario de Mariátegui.

José Carlos Mariátegui comprendió el marxismo como un método dialéctico y como una filosofía de la praxis, fundó el Partido Socialista como vanguardia del movimiento obrero y planteó el "socialismo indoamericano" como una alternativa democrática frente a la sociedad oligárquica y al socialismo stalinista de la III Internacional Comunista.

Por el contrario, desde la muerte de José Carlos Mariátegui en 1930, los ideólogos del Partido Comunista se dedicaron a citar las ideas de Lenin, Stalin y Mariátegui como si fueran versículos de una Biblia que había que aprender de memoria. Pero eso no es todo, la miseria intelectual del Partido Comunista es tan evidente que, desde su fundación, no logró publicar ninguna obra importante sobre los problemas de la realidad peruana.

No se puede engañar a la dialéctica de la historia. Después de la muerte de Mariátegui comenzó el periodo de la decadencia intelectual, la dogmatización del marxismo y la traición del socialismo revolucionario. Así por ejemplo, los dirigentes del Partido Comunista Peruano traicionaron las ideas del amauta porque convirtieron el marxismo dialéctico y creativo de Mariátegui en un marxismo dogmático, petrificado y vulgar y porque el proyecto histórico del socialismo indoamericano del amauta fue completamente olvidado y porque el Partido Socialista de Mariátegui pasó por un proceso de degeneración política convirtiéndose en un partido comunista totalmente burocrático, ineficaz y decadente.

\section{Décima primera tesis \\ Una discrepancia con Alberto Flores Galindo}

Analizar las ideas de Flores Galindo sobre el marxismo de Mariátegui es muy difícil para mí, porque siento que la vida me ha planteado una ironía de la historia. Alberto Flores Galindo falleció justamente cuando recién comenzaba mis estudios sobre José Carlos Mariátegui y por lo tanto, cuando más lo necesitaba como amigo. Ironía de la historia porque a pesar de nuestros acuerdos ideológicos la vida nunca nos ofreció una oportunidad para poder luchar juntos no solamente contra el marxismo dogmático, que convierte las ideas de Mariátegui en una colección de citas bibliográficas, sino también contra el stalinismo que sigue traicionando el socialismo revolucionario de Mariátegui. Frente a estas circunstancias difíciles icómo criticar a Alberto Flores Galindo investigador que, sobre las ideas del amauta, tengo algunas discrepancias? ¿Cómo criticar al autor de La Agonía de Mariátegui cuyo testamento político comparto íntegramente?

La agonía de Mariátegui es uno de los libros más interesantes que se han escrito sobre el marxismo y el socialismo de Mariátegui. En términos generales estoy de acuerdo con el análisis sobre la polémica de Mariátegui con la III Internacional Comunista, es decir, las discrepancias que tuvo el amauta con Vittorio Codovilla, 
el representante del comunismo internacional en la I Conferencia Comunista en Buenos Aires en junio de 1929. Así también estoy de acuerdo con los argumentos de Flores Galindo sobre la polémica de Mariátegui con Víctor Raúl Haya de la Torre.

Pero discrepo con el autor de la utopía andina cuando dice que Mariátegui "consiguió proponer un marxismo tan diferente como el de Gramsci y el de Lukács" (1989, p.23). Aquí Flores Galindo, se equivoca porque existe una similitud evidente entre el pensamiento de Gramsci, Lukács y Mariátegui porque aplicaron críticamente el método dialéctico y el materialismo histórico de Carlos Marx y porque los tres interpretaron el marxismo como una filosofía de la praxis.

Así también, estoy de acuerdo con el argumento de Flores Galindo de que sin la tesis de la "agonía" de Miguel de Unamuno, contenida en el libro La Agonía del Cristianismo, no se puede comprender, en su integridad, el marxismo del fundador del socialismo peruano. Sobre este aspecto no hay ninguna duda porque Mariátegui en el artículo "La agonía del cristianismo de don Miguel de Unamuno" afirma que "el marxismo es lucha, es agonía” (1994, t. I, p. 622). Pero estoy en desacuerdo con Flores Galindo cuando contrapone agonía y dialéctica. Es decir, cuando descarta la relación entre estos dos términos. Así por ejemplo, el autor de la utopía andina dice que "agonía es pasión, fe, elan. Agonía se confunde finalmente con esa esperanza que define en la política y en la vida cotidiana el derrotero de Mariátegui: la confianza en el futuro que no reposa en las leyes de la dialéctica ni en los condicionamientos de la economía, sino en las voluntades colectivas. En otras palabras, se trata del voluntarismo y el esponaneísmo que emergen en diversos pasajes de su pensamiento."(1989, p. 25). Creemos que la tesis anterior de Flores Galindo contradice el pensamiento del amauta porque para Mariátegui no solamente no existe contradicción entre agonía y dialéctica sino que precisamente la dialéctica marxista es el nervio vital de la agonía de Mariátegui.

En La Agonía de Mariátegui, Flores Galindo dice que Mariátegui "frente a la necesidad de resumir lo esencial del pensamiento de Marx, no pensó en ninguna categoría de análisis (mercancía por ejemplo) en ninguna disciplina (la economía política), tampoco en algún nuevo continente científico (el materialismo histórico), ni siquiera en un método (la dialéctica), pensó estrictamente en que su mérito excepcional, consistía en haber descubierto al proletariado, es decir, al sujeto de la revolución" (1989, p. 75).

Esta explicación de Flores Galindo no solo es ambigua sino que también contiene toda una filosofía, es decir, una manera de pensar el marxismo de Mariátegui sin el método dialéctico y sin el materialismo histórico del amauta que como sabemos se diferencia del materialismo histórico stalinista.

En el libro Defensa del Marxismo Mariátegui explicó que el marxismo es un método esencialmente dialéctico, una concepción del mundo y una filosofía de la praxis que se propone la transformación de la sociedad. Así también, Mariátegui criticó el materialismo histórico dogmático pero aceptó la metodología del materialismo histórico de Carlos Marx, como una interpretación económica de la historia. Sin embargo, Flores Galindo interpreta el marxismo del autor de los 7 Ensayos como si el método dialéctico y el materialismo histórico no existieran en el pensamiento revolucionario de Mariátegui.

Por lo tanto, la diferencia entre el marxismo de José Carlos Mariátegui y el marxismo de Alberto Flores Galindo se encuentra en que el marxismo de Mariátegui no solamente se fundamenta en el materialismo histórico de Carlos Marx sino que también es un método esencialmente dialéctico. Por el contrario, el marxismo de Flores Galindo es un marxismo que también se fundamenta en las ideas revolucionarias de Carlos Marx, pero es un marxismo sin método dialéctico, es decir, sin filosofía marxista.

Curioso el caso de nuestro autor de la utopía andina. Acepta el marxismo de Mariátegui pero no su método dialéctico. Esta peculiaridad de Flores Galindo me ha hecho recordar una idea de León Trotsky cuando criticaba a los intelectuales izquierdistas norteamericanos que "aceptaban el marxismo sin la dialéctica" algo así como "una campana sin soga" (1972, p. 18). Esta genial tesis de Trotsky no solamente puede ser aplicada al marxismo de Flores Galindo sino que también puede ser utilizada como punto de vista crítico en contra de todos los intelectuales que creen en el marxismo de Mariátegui pero no en su método dialéctico, es decir, en su filosofía marxista.

Así también, no estoy de acuerdo con Flores Galindo cuando en el artículo titulado "iMariátegui marxistaleninista?" afirma de que Mariátegui "no entendió materialismo como sinónimo de ateísmo" y que por lo tanto "nos encontramos en una corriente marxista que se aleja del leninismo" (1983).

Pero el problema central no se encuentra en las diferencias entre el pensamiento de Lenin y Mariátegui si no en las similitudes ideológicas entre estos dos personajes históricos. Así por ejemplo, entre Lenin y Mariátegui existe una semejanza fundamental. Ambos comprendieron que no puede haber marxismo sin filosofía y que precisamente la filosofía marxista no es 
neutral sino que es una ideología totalmente partidaria porque defiende la causa del proletariado. Así también, Lenin y Mariátegui comprendieron que el marxismo es una filosofía de la praxis, es decir, una concepción revolucionaria de la filosofía que une la teoría y la práctica para transformar la realidad.

Desde mi punto de vista, Mariátegui fue un marxista leninista crítico y creativo. Pero en el artículo "¿Mariátegui marxista- leninista?", Flores Galindo no tiene la misma opinión y por eso me parece increíble que no diferencie, claramente, entre el "marxismo-leninismo" de Mariátegui de otras ideologías marxistas leninistas vulgares. Así también, en lugar de explicar que sin el método dialéctico de Carlos Marx y que sin las tesis políticas de Lenin no se puede comprender el pensamiento revolucionario del amauta, sorprendentemente, Flores Galindo cuestiona el leninismo de Mariátegui que como todos sabemos se diferencia del "marxismo leninismo" de Stalin.

El método dialéctico de Carlos Marx y las tesis políticas de Lenin constituyen el fundamento central del marxismo de Mariátegui. Por lo tanto, intentar separar el Mariátegui marxista del Mariátegui leninista no sólo es una tarea imposible sino que significa traicionar el pensamiento revolucionario del fundador del Partido Socialista.

Hay que estar ciegos para confundir el "marxismoleninismo" de Mariátegui con el "marxismo-leninismo" de Stalin, Eudocio Ravines, Jorge del Prado y Sendero Luminoso, ideologías que figuran en el museo de la historia del pensamiento social porque han dogmatizado y traicionado completamente el marxismo dialéctico y el socialismo revolucionario de Mariátegui.

\section{Décima segunda tesis}

Los análisis críticos de Aníbal Quijano y César Germaná sobre la vigencia de las ideas de Mariátegui

Aníbal Quijano ha publicado varios libros y artículos donde analiza las ideas del marxismo y el socialismo de Mariátegui. Así por ejemplo, en 1981 publicó el libro Reencuentro y debate: una introducción a Mariátegui, texto editado en Lima por la editorial Mosca Azul.

En 1991 el Fondo de Cultura Económica, Lima, editó la compilación de Quijano titulada José Carlos Mariátegui. Textos básicos. En el prólogo de este libro Quijano plantea algunas ideas interesantes como: el derrumbamiento del "socialismo realmente existente", es decir, del socialismo stalinista de lo que fue la Unión de Repúblicas Socialistas Soviéticas; la crisis del materialismo histórico stalinista, muy diferente a la concepción del materialismo histórico de Mariátegui y también
Quijano explica que el "socialismo indoamericano" de Mariátegui es un proyecto histórico completamente diferente al socialismo stalinista de la III Internacional Comunista.

Para Quijano la vigencia de las ideas de Mariátegui se encuentra en la "racionalidad distinta" de Mariátegui, en las "maneras de mirar, de perspectivas, del modo de urdir una relación cognitiva con el mundo"; del "modo de pensar, de indagar y de conocer"; en su proyecto histórico del "socialismo indoamericano" como antítesis del socialismo stalinista; en la propuesta socialista de la "democracia directa de los trabajadores." Pero también la vigencia de Mariátegui se encuentra en la "concepción histórica y dialéctica de la totalidad" y en la manera crítica en que Mariátegui interpreta el materialismo histórico de Carlos Marx para estudiar los problemas fundamentales de la sociedad de su tiempo y que, como sabemos, se diferencia fundamentalmente del materialismo histórico stalinista.

Posteriormente en el $V$ Congreso Nacional de Filosofía reunido en Lima, el 2 de agosto de 1994, Aníbal Quijano explica su hipótesis de la "racionalidad alternativa" en una conferencia titulada "El marxismo de Mariátegui: una propuesta de racionalidad alternativa."

En esta conferencia Quijano plantea la hipótesis de que la racionalidad alternativa de Mariátegui es "una propuesta autónoma tanto frente a ese historicismo chato y positivismo pávido que el encontraba en la social-democracia europea de su tiempo, como frente al llamado bolchevismo y al marxismo leninismo, sobre todo tal como este comenzaba a desarrollarse desde mediados de los años veinte" (1995, p.41).

Quijano afirma que es necesario "reconstruir la racionalidad alternativa que planteó Mariátegui, a fin de intentar de nuevo lo que fue derrotado, es decir, actuar, transformar y conocer la realidad desde dentro de ella misma. Sugiero exactamente otra vez que en esto consiste el legado principal de Mariátegui: su esfuerzo por cambiar la realidad y, al mismo tiempo y en un mismo movimiento, el esfuerzo por constituir los elementos de una racionalidad alternativa" (1995, p. 68).

Pero Quijano puntualiza que la "racionalidad alternativa" de Mariátegui no es una propuesta contra el marxismo de Carlos Marx sino todo lo contrario, tiene como fundamento las ideas de Carlos Marx.

Desde mi punto de vista, Mariátegui fue un marxista clásico que desarrolló creativamente las ideas de Marx y de Lenin para aplicarlas a la realidad del Perú y de América Latina. En consecuencia, no creo que Mariátegui tuviera "otra racionalidad" diferente del marxismo dialéctico, del marxismo revolucionario, es decir, del 
marxismo clásico como lo definía Isaac Deutscher en el libro El marxismo de nuestro tiempo.

César Germaná es un sociólogo peruano que se ha interesado por el estudio de las ideas de Mariátegui. En 1977 publico el artículo "La polémica. Haya de la TorreMariátegui: Reforma o revolución en el Perú”. Texto editado por la revistaAnálisis, (números 2-3), Lima.

En este artículo Germaná explica el desarrollo de la polémica entre Mariátegui y Haya de la Torre sobre la naturaleza de la sociedad peruana, las características del imperialismo en una sociedad semifeudal y semicolonial, las clases sociales explotadas y el carácter de la revolución socialista en el Perú.

Posteriormente en 1995, César Germaná publica el libro El Socialismo Indo-americano de José Carlos Mariátegui: Proyecto de reconstitución del sentido bistórico de la sociedad peruana. En esta obra Germaná bosqueja la idea de que Mariátegui planteó el "socialismo indoamericano" como un proyecto alternativo a la crisis de la civilización capitalista y también al socialismo stalinista de la III Internacional Comunista.

En el libro Germaná afirma que "el socialismo aparece en las reflexiones de José Carlos Mariátegui alrededor de tres ejes: primero, como la socialización de los recursos productivos, esto es, el establecimiento de relaciones de cooperación y de solidaridad en la producción; segundo como la socialización del poder político, en el sentido del ejercicio directo del poder por la sociedad en su conjunto; $y$ tercero, (...) como un nuevo sentido de vida, es decir, una racionalidad alternativa a la del capitalismo" (1995, p.221).

Es importante indicar las diferencias que hay entre las interpretaciones de Aníbal Quijano y Alberto Flores Galindo sobre la vigencia del pensamiento de Mariátegui. Así por ejemplo, la propuesta de Quijano es interesante porque reconoce la concepción dialéctica de la historia, es decir, el materialismo histórico, crítico y creativo de Mariátegui. En cambio, la interpretación de Alberto Flores Galindo es contradictoria porque cree en el marxismo de Mariátegui pero no en el método dialéctico, es decir, en la filosofía marxista de Mariátegui. Así también, Flores Galindo puntualiza la concepción histórica del marxismo del fundador del socialismo peruano pero no cree en el materialismo histórico de Mariátegui, método de análisis para analizar la sociedad que el amauta utilizó de manera crítica y creativa y que se diferencia del materialismo histórico de Stalin.

\section{Décima tercera tesis \\ La vigencia de las ideas de Mariátegui según José Aricó y Carlos Franco \\ José Aricó es un investigador apasionado por las ideas de}

Mariátegui. En 1978 publicó el libro Mariátegui y los orígenes del marxismo latinoamericano. El libro es interesante y polémico porque contiene más de veinte artículos de diversos autores que discuten sobre el marxismo, el populismo, el aprismo, el sorelismo, el partido socialista de Mariátegui y las interpretaciones sobre el libro los 7 Ensayos de Interpretación de la Realidad Peruana. Pero también la introducción de Aricó no solamente es un texto fundamental porque analiza los aspectos centrales sobre el marxismo y el socialismo de Mariátegui, el debate de Mariátegui con la III Internacional Stalinista y la concepción del partido socialista del amauta sino que también es importante para comprender el punto de vista de Aricó sobre la actualidad de la vigencia del pensamiento de Mariátegui. En la entrevista titulada: "Nación y Democracia: en la raíz del movimiento socialista", Aricó nos dice que "no es la letra de los textos de Mariátegui, sino en el espíritu que inspira esos textos, donde nosotros podemos encontrar una forma de considerar la realidad que es, yo creo, lo profundamente rescatable de Mariátegui" (1980, p.116).

Esto quiere decir que para Aricó la vigencia del pensamiento del amauta no se encuentra "en la letra de los textos de Mariátegui" sino que se halla en la manera de cómo Mariátegui logró "recrear al marxismo" (1980, p. 116) teniendo en cuenta las características peculiares de la sociedad peruana. Estamos de acuerdo con esta tesis de Aricó; pero discrepamos con él cuando, en esta misma entrevista dice que "hoy el socialismo no pasa por un partido” (1980. p. 117). Esta tesis contradice la concepción marxista del Partido Socialista de Mariátegui porque es posible un "socialismo domesticado" sin la necesidad de un partido; pero es imposible pensar en el socialismo como "creación heroica" de Mariátegui sin un partido revolucionario como vanguardia de las clases explotadas.

Las interpretaciones de José Aricó son importantes cuando aclaran las diferencias que existen entre el socialismo de Mariátegui y el socialismo stalinista; pero Aricó se aleja del marxismo revolucionario de Mariátegui cuando trata de disminuir la importancia del partido socialista como organización política fundamental de las clases trabajadoras.

Carlos Franco es un intelectual peruano que se ha interesado por los problemas del marxismo, el socialismo y la nación en el Perú. En el libro titulado Del Marxismo eurocéntrico al marxismo latinoamericano. Franco afirma que José Carlos Mariátegui y Víctor Raúl Haya de la Torre "distinguieron el problema de la nación del de las nacionalidades. Mariátegui, en este sentido, se 
opuso a considerar el problema quechua y aymara como el de nacionalidades oprimidas cuya libración debía adoptar la forma de Estados independientes, separados del Estado peruano. Por ello, su punto de vista fue contrario al del Buró Sudamericano de la Tercera Internacional" (1981, p.84). Esta observación de Franco es interesante y sobre ella no tenemos ningunaduda.

Así también, estamos de acuerdo con Franco cuando expone que el Partido Socialista de Mariátegui no sólo se distanciaba del APRA de Haya de la Torre porque era un partido marxista y leninista sino que también se diferenciaba de los partidos stalinistas de la III Internacional Comunista.

Pero no estamos de acuerdo con Franco cuando afirma que "Mariátegui consideraba preferible la constitución de un movimiento nacional de masas que la formación de un partido de cuadros" (1981, p. 96). Pero aquí existe un problema que Franco no ha podido distinguir. Una cosa es el Partido Socialista, es decir, la vanguardia del movimiento obrero formado por las personas más preparadas y otra cosa es el movimiento obrero como clase social. Mariátegui fundó el Partido Socialista precisamente para unir al proletariado, organizar el movimiento de masas, formar conciencia de clase y realizar la revolución socialista en el Perú.

Carlos Franco es otro de los investigadores que han planteado el problema de la vigencia del pensamiento de Mariátegui. La propuesta de Franco se encuentra en una interesante reunión titulada: "Consecuencia de los cambios del periodo velasquista en el Perú contemporáneo", publicado en El Perú de Velasco, Centro de Estudios para el desarrollo y al Participación, tomo 3, Lima, 1983. En esta reunión, en el que también participan Alberto Flores Galindo, Rolando Ames, Francisco Guerra García y Gonzalo Portocarrero, se discutieron varias cuestionen teóricas importantes. Pero es necesario hacer algunas observaciones. Así por ejemplo, estamos de acuerdo con Carlos Franco cuando afirma que las interpretaciones de Mariátegui y Haya de la Torre sobre la realidad peruana de la década de 1920, el Programa del Partido Socialista de 1928 y el Programa del Partido Aprista de 1931 han perdido actualidad porque la sociedad peruana ha cambiado profundamente y que por lo tanto es necesario elaborar una nueva interpretación de nuestra realidad tomando en cuenta los problemas fundamentales del Perú contemporáneo.

Hasta aquí comparto la opinión de Franco. Pero no estoy de acuerdo con él cuando dice concretamente que: "Yo no creo más en que el poder radique en la propiedad, aunque será necesario en el futuro producir cambios de propiedad. Creo ahora, como dije antes, en la necesidad de cambiar los términos del intercambio entre sectores, que es donde radica, al menos en parte, la fuente de poder de hoy." (1983, t. III, pp. 960-961).

Así también, discrepo con Franco cuando afirma que "debemos cancelar las ideas de Mariátegui y Haya sobre las relaciones clase-partido. Estas relaciones, si alguna vez existieron, se han roto. Nuevos agentes sociales y corporativos organizados compiten ahora con los partidos en la movilización y expresión de los intereses. Ello significa que ha llegado el momento de asumir que no será un partido, ni un frente de partidos, sino un movimiento nacional con una nueva conducción política, el que se convertirá en el agente de las transformaciones" (1983, t. III, p. 961). Frente a estas dos propuestas concretas es indispensable decir que nuestro punto de vista es contrario a las tesis de Carlos Franco. Así por ejemplo, para nosotros, siguiendo el pensamiento revolucionario de Mariátegui, el poder económico y político no radica en el "intercambio entre sectores" ni en la "redistribución Intersectorial de recursos" como dice Franco, sino que una de las características elementales del problema del poder se encuentra en la propiedad de los medios de producción. Es decir, que clases sociales son las que tienen el poder económico en sus manos.

Para comprender este problema es necesario comparar la propuesta de Carlos Franco con la tesis dialéctica de Carlos Marx contenida en la Introducción General de la Crítica de la Economía Política de 1957. Así por ejemplo, Franco relaciona el problema del poder, la propiedad y la "redistribución intersectorial de recursos", como el mismo lo dice; pero olvida un aspecto esencial: la dialéctica del proceso productivo. En cambio, el texto antes mencionado de Carlos Marx no solamente es importante porque explica integralmente el problema de la producción, la propiedad, el consumo, la distribución y el cambio de los productos sino que además es necesario aclarar que la tesis de Marx es exactamente contraria la tesis de Franco porque el poder no radica en las políticas distributivas o en el intercambio sino que la esencia del problema del poder económico y político se encuentra en las características concretas del proceso productivo, en la propiedad de los medios de producción y sus relaciones con las clases sociales. Así también, criticamos las propuestas políticas de Franco porque tratan de comprender el problema del poder económico y político al margen de la teoría de la plusvalía y la lucha de clases. 
Décima cuarta tesis

El Partido Comunista de Sendero Luminoso y la concepción dogmática del marxismo de Mariátegui

El marxismo de Mariátegui, es una concepción del mundo para la vida y no para la muerte, es una filosofía de la praxis que se diferencia de todo marxismo fosilizado en el tiempo. José Carlos Mariátegui llamó "socialismo indoamericano" a su proyecto político alternativo al capitalismo rapaz. Y en una nación en formación, como el Perú de entonces, donde tres cuartas de la población vivían en el campo era lógico pensar que la base social del socialismo fuera el campesinado de los andes. Pero por una ironía de la historia del amauta nunca imaginó que después de su muerte surgiría Sendero Luminoso, una organización política que se hace llamar justamente "por el luminoso sendero de Mariátegui" y que asesinaría a sangre fría a cientos de campesinos peruanos.

Mariátegui comprendió el marxismo como un método dialéctico, es decir, como un procedimiento contrario al pensamiento dogmático y planteó los principios del "socialismo peruano" como un proyecto histórico para defender la vida de las clases trabajadoras. Posteriormente, Mariátegui fundó el Partido Socialista como vanguardia de la clase obrera y no como un partido de la muerte. Pero por una ironía de la historia, Sendero Luminoso convierte el marxismo dialéctico de Mariátegui en un marxismo dogmático, transforma el socialismo revolucionario en un socialismo autoritario y degenera el partido socialista del amauta en un partido de la muerte. Es decir, el pensamiento de Mariátegui sufre la más grande metamorfosis ideológica en manos de Sendero Luminoso.

En una conferencia grabada el año de 1968, en la Casona de la Universidad Nacional Mayor de San Marcos, Abimael Guzmán dijo refiriéndose a Mariátegui que "tenemos que seguir su camino, realmente al pie de la letra" (1984). Esta tesis que plantea estudiar el marxismo de Mariátegui "al pie de la letra” demuestra concretamente que Abimael Guzmán nunca pudo romper "el cordón umbilical" que lo unía ciegamente al marxismo dogmático.

Mariátegui publicó los 7 ensayos de interpretación de la realidad peruana en 1928. En este texto el amauta explica el carácter "semifeudal" y "semicolonial" de la sociedad peruana. Pero han pasado más de 80 años desde la primera edición de los 7 ensayos y, lógicamente, el Perú de Mariátegui no es el Perú de hoy. Pero para Abimael Guzmán la sociedad peruana no ha cambiado porque en la conferencia de 1968 que hemos mencionado y en el documento Retomemos a Mariátegui y reconstituyamos su partido (1975, p. 12). Abimael Guzmán sigue defendiendo la tesis del "carácter semifeudaly semicolonial de nuestra sociedad.”

Lo mismo podemos decir de Antonio Díaz Martínez cuando en su libro Ayacucho: Hambre y esperanza planteó la tesis de que el Perú de la década de 1980 continuaba siendo un país "semi-colonial y semifeudal" (1985, p.200).

Por lo tanto, no hay ninguna duda de que Abimael Guzmán y Antonio Díaz Martínez petrificaron el carácter de la sociedad peruana definida por Mariátegui.

En su trabajo titulado "Problemas de la guerra y de estrategia”, Mao Tse Tung planteó la siguiente tesis sobre el partido comunista: "Todos los comunistas tienen que comprender esta verdad: El poder nace del fusil. Nuestro principio es: el partido manda al fusil, y jamás permitiremos que el fusil mande al partido." (1976, t. II, p. 231). Varias décadas después el gran político chino nunca imaginó, como es lógico, que Sendero Luminoso, una organización terrorista surgida en el corazón de los andes peruanos, iba a tomar como ideología el pensamiento maoísta y después transformaría completamente la tesis de que "el partido manda al fusil" en la sangrienta tesis de que "el fusil manda el partido." Pero el Partido Comunista de Abimael Guzmán también degeneró completamente la idea del conocido estratega militar Carlos Von Clausewitz de que "la guerra es la prolongación de la política".

Los 7 Ensayos de Interpretación de la realidad peruana de Mariátegui, Las cinco tesis filosóficas de Mao Tse Tung y el libro Cuestiones de leninismo de Stalin, constituyen "las tres Biblias" de los militantes de Sendero Luminoso.

Pero también, la ideología del Partido Comunista de Sendero Luminoso es una concepción para la muerte y se caracteriza por ser una peculiar síntesis dogmática entre el marxismo de Carlos Marx y Lenin; el "marxismo-leninismo" de Stalin; el marxismo de Mao Tse Tung; el marxismo de Mariátegui y el "pensamiento Gonzalo", es decir, las ideas dogmáticas de Abimael Guzmán.

En consecuencia, hay que estar ciegos para no darse cuenta que el marxismo dialéctico de Mariátegui se diferencia completamente del marxismo dogmático de Sendero Luminoso.

\section{Décima quinta tesis}

David Sobrevilla: Sepulturero del marxismo dialéctico de José Carlos Mariátegui

Así como en el libro Herejes y renegados, Isaac Deustcher planteó la idea de los stalinistas al revés para referirse a los escritores y dirigentes políticos que lucharon 
por el comunismo y que después traicionaron el marxismo y el socialismo stalinista; así también consideramos como "mariateguistas al revés" a los intelectuales y políticos que alguna vez creyeron en las ideas de Mariátegui y que ahora ya no creen en la vigencia de su pensamiento revolucionario.

Ha llegado la hora de criticar el dogmatismo y las falsificaciones sobre las ideas revolucionarias del fundador del Partido Socialista. El marxismo vivo de Mariátegui no puede comprenderse al margen de la historia de las ideas socialistas del siglo XX. Al lado de Marx, Lenin, Trotsky, Plejanov, Lukács y Gramsci; Mariátegui fue un socialista revolucionario que utilizó creativamente la metodología marxista para comprender la dialéctica de la historia.

El libro El marxismo de Mariátegui y su aplicación a los 7 ensayos de David Sobrevilla es un libro interesante porque es el único texto, publicado hasta el momento, que analiza ampliamente los 7 ensayos de interpretación de la realidad peruana de Mariátegui. Pero la obra de Sobrevilla también es importante porque es un libro diseñado para negar, en contra de la realidad, el método dialéctico y la filosofía marxista de José Carlos Mariátegui.

Los 7 ensayos de interpretación de la realidad peruana es el mejor ejemplo de cómo Mariátegui aplicó críticamente el materialismo histórico para analizar los problemas fundamentales de la sociedad peruana. Así por ejemplo no se puede comprender el "Esquema de la evolución económica", "El problema del indio" y "El problema de la tierra", sin la interpretación económica de la historia de Carlos Marx, metodología para el análisis de la historia que el amauta interpretó creativamente.

Así también, Defensa del marxismo es el libro donde Mariátegui sintetiza su interpretación del marxismo como una concepción materialista de la historia, una ciencia práctica de la revolución, un método dialéctico y como una filosofía de la praxis. Sin embargo, todavía existen intelectuales que aceptan el materialismo histórico del amauta, pero cuestionan la concepción filosófica del marxismo de Mariátegui. Pero, desde nuestro punto de vista, están condenadas al fracaso todos los estudios históricos, todos los argumentos filosóficos y todas las tesis políticas que cuestionan, dogmatizan y traicionan el método dialéctico y la filosofía marxista de Mariátegui.

En sus explicaciones para negar el marxismo filosófico del amauta, Sobrevilla afirma que el marxismo de Mariátegui "es un materialismo meramente histórico y no filosófico o dialéctico” (2005, p. 214). Pero Sobrevilla oculta que el amauta puntualizó que: "El marxismo del cual todos hablan pero que muy pocos conocen y, sobre todo, comprenden, es un método fundamentalmente dialéctico. Es un método que se apoya íntegramente en la realidad, en los hechos. No es, como algunos erróneamente suponen, un cuerpo de principios de consecuencias rígidas, iguales para todos los climas históricos y todas las latitudes sociales. Marx extrajo su método de la entraña misma de la historia." (1969, pp. 111-112).

Hemos afirmado que Mariátegui comprendió el marxismo como una concepción materialista de la historia, como un método dialéctico y como una filosofía de la praxis. Pero también leyó el libro Materialismo y empiriocriticismo de Lenin y comprendió que el socialismo se forma en la lucha de clases y que la filosofía marxista no es una concepción para la contemplación de la realidad sino que nos sirve para transformar la sociedad y que por lo tanto no puede existir una filosofía imparcial y neutral y que en consecuencia toda filosofía es partidaria, es decir, tiene un carácter de clase.

Para Mariátegui no puede haber marxismo sin filosofía y sin método dialéctico, es decir, el nervio vital del marxismo como decía Lukács en el libro Historia y conciencia de clase. Precisamente la filosofía marxista es el vínculo inseparable entre el partido socialista y la lucha de clases del movimiento obrero. Sin embargo, a pesar de todo lo mencionado, Sobrevilla acepta el materialismo histórico del amauta pero no el método dialéctico, es decir, la filosofía marxista de Mariátegui.

Es necesario recordar al lector que David Sobrevilla, no es el único intelectual que niega el carácter filosófico del marxismo de Mariátegui. Así por ejemplo, en el artículo publicado en 1940 titulado "Mariátegui y el materialismo dialéctico", Jorge Núñez Valdivia escribió que "José Carlos Mariátegui no fue un materialista dialéctico consecuente." (1980, p. 307). Así también, en el libro Haya de la Torre y Mariátegui frente a la bistoria, José Barba Caballero afirmó que "la gran limitación de Mariátegui fue la falta de una concepción filosófica que lo ayudase a abrir camino" (1978, p. 249). La tesis de Barba Caballero es totalmente absurda porque la filosofía marxista era el punto central de la concepción del mundo de Mariátegui.

En la sección "Lo vivo y lo muerto del pensamiento de Mariátegui" del libro El marxismo de Mariátegui y su aplicación a los 7 ensayos, David Sobrevilla dice lo siguiente: "Nuestra conclusión es, por consiguiente, que en el marxismo de José Carlos preponderan los elementos muertos, por lo que de proseguirse el camino de Mariátegui, su concepción del marxismo debería ser ampliamente reconstruida: ante todo se tiene que rechazar el punto 
de vista del partidarismo en cuanto al conocimiento, el determinismo económico tiene que ser reelaborado en una forma más satisfactoria, se debería renunciar a la concepción del marxismo clásico de que la sociedad está compuesta de base- formada por fuerzas y relaciones de producción- y superestructura determinada en última instancia por aquella, y se debería procesar de otra manera la idea de la lucha de clases. Importante sería en cambio preservar el componente ético del marxismo. Por otra parte, se debería abandonar la idea de que la revolución tenga que ver con la propuesta de un mito que no se dirige a la razón de los revolucionarios sino a su intuición, imaginación y afectividad. Finalmente es positivo que el marxismo mariateguiano no haya hecho uso de un recurso tan problemático como la dialéctica" (2005, p. 424).

En su ofuscación de separar lo vivo y lo muerto de las ideas de Mariátegui parece increíble que un intelectual como Sobrevilla afirme que "en el marxismo de José Carlos preponderan los elementos muertos" (2005, p. 424), cuando básicamente es todo lo contrario porque no es el marxismo vivo de Mariátegui el que se encuentra en crisis si no el marxismo dogmático y stalinista que está en pleno proceso de descomposición ideológica.

Así también, Sobrevilla afirma que "es positivo que el marxismo mariáteguiano no haya hecho uso de un recurso tan problemático como la dialéctica" (2005, p. 424). En esta frase Sobrevilla, no solamente niega la filosofía marxista del amauta sino que también falsifica la realidad porque no se puede comprender el pensamiento revolucionario de Mariátegui sin el método dialéctico de Carlos Marx.

Pero Sobrevilla sigue confundiéndonos cuando dice que "se debería renunciar a la concepción del marxismo clásico de que la sociedad está compuesta de baseformada por fuerzas y relaciones de producción- y superestructura determinada en última instancia por aquella." (2005, p. 424).

Aquí Sobrevilla confunde marxismo clásico con marxismo vulgar porque la interpretación del marxismo clásico sobre el problema de la base y la superestructura es muy diferente al análisis del marxismo vulgar sobre el determinismo económico de la base y la superestructura. No comprender esta diferencia es dogmatizar y petrificar el marxismo clásico.

Sobrevilla también afirma que "se tiene que rechazar el punto de vista del partidarismo en cuanto al conocimiento." (2005, p. 424). Con esta frase Sobrevilla sepulta el marxismo vivo del amauta porque para Mariátegui no existe contradicción entre el conocimiento de la realidad y la adopción de una posición partidaria.
Mariátegui entendió muy bien la tesis fundamental del libro Materialismo y Empiriocriticismo de Lenin, de que la dialéctica es la teoría del conocimiento, que la filosofía marxista no es imparcial y que tiene un carácter de clase, que no puede haber conocimiento al margen de la práctica, que no puede existir marxismo sin filosofía y que, precisamente, optar por una filosofía es tomar una posición partidaria y que por lo tanto sería ingenuo practicar la filosofía marxista al margen de la lucha de clases.

Las ideologías políticas pueden evolucionar de acuerdo a los nuevos escenarios históricos del mundo contemporáneo. Pero también las ideas políticas pueden seguir el camino de la dogmatización, falsificación y la traición y pasar al archivo de la historia del pensamiento social.

Sobrevilla no entiende la lección. La filosofía marxista no solo es el método dialéctico que explicaba el cambio, el movimiento y la transformación de la realidad sino que también es una concepción de la revolución que penetra en la sangre y en pensamiento intuitivo. Esta visión del mundo es inherente a los marxistas clásicos como Marx, Lenin, Trotsky, Gramsci y Rosa Luxemburgo, por solo citar algunos nombres.

José Carlos Mariátegui fue un marxista dialéctico revolucionario que comprendió la filosofía marxista como una concepción del mundo para cambiar la sociedad. Pero igualmente percibió el marxismo como una ideología que penetraba en su sangre. No olvidemos que en la Advertencia de los 7 Ensayos de interpretación de la realidad peruana, Mariátegui escribió lo siguiente: "Mi pensamiento y mi vida constituyen una sola cosa, un único proceso. Y si algún mérito espero y reclamo que me sea reconocido es el de - también conforme un principio de Nietzsche - meter toda mi sangre en mis ideas" (1952, p. 7). Así escribió Mariátegui porque fue un materialista dialéctico. En consecuencia, no me sorprende que Sobrevilla, un filósofo que no es un materialista dialéctico, no entienda la relación inseparable entre la sangre y las ideas de un marxista romántico y un socialista revolucionario como Mariátegui.

Así también, Sobrevilla no ha estudiado las tesis sobre el "marxismo clásico" y el "marxismo vulgar" explicadas en el libro El marxismo de nuestro tiempo de Isaac Deutscher. No ha analizado los argumentos sobre el "marxismo científico" y el "marxismo crítico" del libro Los dos marxismos de Alvin Gouldner. No tiene idea de que las tesis filosóficas del libro Materialismo y empiriocriticismo de Lenin, influenciaron en la concepción del marxismo dialéctico de Mariátegui. Pero Sobrevilla tampoco comprende la similitud ideológica 
entre Gramsci y Mariátegui respecto a la filosofía de la praxis.

En un escrito titulado "Contribución a la crítica de la filosofía del derecho de Hegel”, Carlos Marx escribió que "la filosofía no puede llegar a realizarse sin la abolición del proletariado, y el proletariado no puede abolirse sin la realización de la filosofía" (1979, p. 116). Sobrevilla no entiende que Mariátegui también inició la realización de la filosofía marxista en el Perú.

La filosofía marxista de Carlos Marx y de Lenin significó para Mariátegui la llama viva del marxismo que explicaba la dialéctica de la historia. Para el amauta el marxismo no era una técnica para el análisis de textos sino que comprendió el marxismo dialéctico como una concepción del mundo y como una filosofía de la praxis para la transformación de la sociedad y no para la contemplación de la realidad.

La filosofía de la praxis de Mariátegui no hay que buscarla en sus tesis políticas estudiadas fuera de su contexto histórico, ni comparando unos textos con otros textos, sino que se encuentra en la concepción que tuvo Mariátegui del marxismo como una concepción del mundo que une la teoría y la práctica para transformar la realidad. Así por ejemplo, la filosofía de la praxis de Mariátegui se encuentra en su práctica revolucionaria para formar conciencia de clase en las Universidades Populares González Prada, en la creación de la revista Amauta, como un proyecto para la unidad del movimiento intelectual, en la fundación del Partido Socialista y las polémicas que tuvo con Víctor Raúl Haya de la Torre y los dirigentes de la Internacional Comunista.

Mariátegui comprendió que el materialismo histórico es la teoría marxista de la historia, la crítica de la sociedad capitalista en decadencia, el método revolucionario que analiza el presente desde una perspectiva histórica y también es una práctica que se realiza en la lucha de clases. Pero Sobrevilla no quiere comprender que para Mariátegui el fundamento filosófico del materialismo histórico es el método dialéctico marxista. Por consiguiente, no se puede explicar el materialismo histórico de Mariátegui sin el método dialéctico.

Es increíble que un filósofo tan preparado como Sobrevilla no comprenda que el marxismo de Mariátegui no es una filosofía de la historia pero sí es un método dialéctico, una filosofía de la praxis y una "interpretación económica de la historia”, como decía Mariátegui.

David Sobrevilla es un sepulturero del marxismo de Mariátegui porque en lugar de explicar las características de la filosofía marxista de Mariátegui, Sobrevilla traiciona las ideas del marxismo filosófico del amauta y porque en lugar de replantear, desde una visión crítica, la relación entre el materialismo histórico, la filosofía marxista y la lucha de clases, sepulta las ideas fundamentales del marxismo revolucionario de Mariátegui.

\section{REFERENCIAS BIBLIOGRÁFICAS}

Aricó, J. (1980). Nación y democracia: En la raíz del movimiento socialista. QueHacer, 7, 100-117.

Bahro, R. (1980). La alternativa. Madrid: Alianza Editorial.

Barba, J. (1978). Haya de la Torre y Mariátegui frente a la historia. Lima: Editorial imprenta Amauta.

Comité Central del Partido Comunista Peruano. (1975). Retomemos a Mariátegui y reconstituyamos supartido. Lima.

Díaz, A. (1985). Ayacucho: hambre y esperanza. Lima: Mosca Azul Editores.

Franco, C. (1981). Del marxismo eurocéntrico al marxismo latinoamericano. Lima: Centro de Estudios para el Desarrollo y la Participación.

Franco, C. (1983). El Perú de Velasco. Lima: Centro de Estudios para el desarrollo y la Participación.

Galeano, E. (1990). El niño perdido en la intemperie. (Los funerales que se equivocaron de muerto).

Germaná, C. (1995). El socialismo indo-americano de José Carlos Mariátegui: proyecto de reconstrucción del sentido bistórico de la sociedad peruana. Lima: Empresa editora Amauta.

Flores, A. (1983). Los mineros de la Cerro de Pasco. 1900-1939. Lima: Pontificia Universidad Católica del Perú.

Flores, A. (1983). ¿Mariátegui marxista leninista?. El Caballo Rojo, núm. 159, suplemento de El diario de Marka.

Flores, A. (1989). La agonía de Mariátegui. Lima: Instituto de Apoyo Agrario.

Guzmán, A. (1984). Conferencia grabada en 1968 en la Casona de la Universidad Nacional Mayor de San Marcos. El diario de Marka. 14.04.84

Mariátegui, J. (1952). 7 Ensayos de interpretación de la realidad peruana. Lima: Empresa Editora Amauta.

Mariátegui, J. (1969). Ideología y política. Lima: Empresa Editora Amauta.

Mariátegui, J. (1994). Ética y socialismo. En: Mariátegui Total, (T. I, pp.1303-1306). Lima: Empresa Editora Amauta. 
Mariátegui, J. (1994). La agonía del cristianismo de don Miguel de Unamuno. Mariátegui Total. (t. I, pp. 620-622). Lima: Empresa Editora Amauta.

Marx, C. (1970). Contribución a la crítica de la filosofía del derecho de Hegel. En: Karl Mar y Arnold Ruge, Los anales franco-alemanes. (pp.101-116). Barcelona: Ediciones Martínez Roca.

Núñez, J. (1980). José Carlos Mariátegui y el materialismo dialéctico. En: José Aricó, Mariátegui y los orígenes del marxismo latinoamericano. (pp. 293-308). México: Cuadernos de Pasado y Presente.

Quijano, A. (1995). El marxismo de Mariátegui: una propuesta de racionalidad alternativa. En: El marxismo de José Carlos Mariátegui, edición e introducción de David Sobrevilla. (pp. 39-47). Lima: Universidad de Lima, Empresa Editora Amauta.

Ravines, E. (1952). La gran estafa. México: Libros y Revistas.
Ravines, E. (1957). El marxismo, los siete ensayos y Mariátegui. Vanguardia, 20,6.

Ravines, E. (1958). La excomunión y la herejía de José Carlos Mariátegui. Vanguardia, 48, 7.

Ravines, E. (1958). Mariátegui no concibió la Reforma Agraria. Vanguardia, 62, 12.

Salazar, A. (1972). Un salvador de Mariátegui. Textual, 4, 56-58.

Salazar, A. (1972). Actualidad de Mariátegui. Textual, 5 y $6,19-22$.

Sobrevilla, D. (2005). El marxismo de Mariátegui y su aplicación a los 7 Ensayos. Lima: Universidad de Lima, Fondo de Desarrollo Editorial.

Trotsky, L. (1972). En defensa del marxismo. Argentina: El Yunque.

Tse Tung, M. (1976). Problemas de la guerra y la estrategia. En: Obras Escogidas. Pekin: Ediciones en lenguas extranjeras. 